\title{
PITYRIASIS ROSEA MIMICKING POLYMORPHIC ERUPTIONS OF PREGNANCY
}

\author{
BALAJI 0 ${ }^{1 *}$, AMITA PRIYA D ${ }^{1}$, SWAMINATHAN TN²
}

${ }^{1}$ Department of Pharmacology, Kasturba Medical College, Manipal University, Manipal, Karnataka, India. ${ }^{2}$ MBBS Student, Bangalore Medical College, Karnataka, India. Email: puntermmc@gmail.com

Received: 03 April 2017, Revised and Accepted: 07 July 2017

ABSTRACT

Pityriasis Rosea is a self-limiting skin disorder of unknown etiology affecting women more than men. It is very rare in pregnancy and evidence shows conflicting reports on pregnancy outcomes related to Pityriasis Rosea. But recent evidence says, pregnancy outcomes are not altered, although clinicians must monitor the patient throughout the gestation for adverse outcomes. Hence, we report a case of Pityriasis Rosea infection in a primigravida, in the first trimester and the follow-up done in a tertiary care hospital in Southern India.

Keywords: Rash, First trimester, Anomaly scan, Human herpes virus.

(C) 2017 The Authors. Published by Innovare Academic Sciences Pvt Ltd. This is an open access article under the CC BY license (http://creativecommons. org/licenses/by/4. 0/) DOI: http://dx.doi.org/10.22159/ajpcr.2017.v10i10.18877

\section{INTRODUCTION}

Pityriasis Rosea is a common self-limiting condition affecting the skin. It is usually acute and affects women more than men with higher incidences among young women. Etiology is unknown and can be due to viral or bacterial infection. It usually begins as a herald patch and slowly scaly oval shaped erythematous lesions evolve all over the trunk, limbs usually sparing the face and scalp. Prodromal symptoms include fatigue, malaise, fever, headache and sore throat. It is usually self-limiting and disappears after 4 weeks. Pharmacological treatment includes topical as well as oral steroids, antibiotics such as macrolides and antihistamines to control itching $[1,2]$. It is very rare in pregnancy, and only a few cases and studies have been done reporting the association of pregnancy with Pityriasis Rosea. Hence, we report a case of 27-year-old primigravida, diagnosed of Pityriasis Rosea at 12 weeks of gestation in a tertiary care hospital in Southern India.

\section{CASE REPORT}

Informed consent was taken from the patient. A 27-year-old female, primigravida, 12 weeks of gestation came with complaints of rashes all over her body for 7 days. Salmon colored scaly patches with peripheral collarette scaling were present all over the body sparing the face and scalp. 1 week before the rashes appeared all over the body, a herald patch was noted in the left thigh. Systemic examination was normal, and vitals and blood pressure were stable. There was no associated fever and other signs of infection. There was no history of autoimmune disorders, no history of any drug intake during pregnancy. Partner was examined and he was found to be normal. Blood tests revealed elevated eosinophil counts and all the other routine blood investigations were normal. There was no itching and icterus was also absent. Pruritic urticarial papules and plaques of pregnancy were considered the first diagnosis but it usually affects women in the third trimester, and there was no associated pruritus. It was ruled out, and final diagnosis of Pityriasis Rosea was made as there were a herald patch and lesions involved the truck in Christmas tree pattern. The patient was treated with clobetasol cream 30/70 mixture for 2 weeks 2 times daily and then for another 2 weeks once daily. Lesions subsided slowly in 2-3 weeks, and there was no recurrence. The patient now is in 27 weeks of gestation and fetus is of normal growth, and anomaly scans were taken to rule out any fetal anomalies, and it was found to be normal. Both the mother and fetus are normal.

\section{DISCUSSION}

Pityriasis Rosea is very rarely reported in pregnancy and etiology is unknown. Human herpesvirus 6 and 7, Epstein Barr virus, parvovirus
B19, and legionella pneumonia have been implicated as causative factors $[3,4]$. Placental barrier may sometimes become weaker due to damage and it may result in the transfer of infections from mother to fetus [5]. A study conducted among 38 pregnant females with Pityriasis Rosea reported $13 \%$ of women developed miscarriage before 15 weeks of gestation which is almost equal to miscarriages among general pregnancy population [6]. Furthermore, a literature search revealed in 6 cases of pregnancy associated with Pityriasis Rosea, new born fetus had increased hypotonia and weak motility [6]. But recent research revealed Pityriasis Rosea during pregnancy has no adverse outcomes on the mother as well as fetus [7]. In our case, other conditions were ruled out which includes pruritic urticarial papules and plaques of pregnancy and history of drug allergy and intake of drugs known to cause skin disorders. The patient is still in 27 weeks of gestation, and there were no associated congenital abnormalities noted in the fetus as per anomaly scan reports.

\section{CONCLUSION}

Even though Pityriasis Rosea is a self-limiting condition, proper monitoring should be done if it is diagnosed during pregnancy. As there is no clear evidence on the adverse outcomes of Pityriasis Rosea on fetus, proper treatment with topical steroids should be given and proper investigations should be done to rule any congenital abnormalities. Furthermore, if Pityriasis Rosea is diagnosed during the first trimester of pregnancy, look for constitutional symptoms, and a proper dermatology opinion should be obtained. Further clinical studies can be done to find out the incidence of Pityriasis Rosea in pregnancy, and to evaluate its outcomes in pregnancy (Fig. 1).

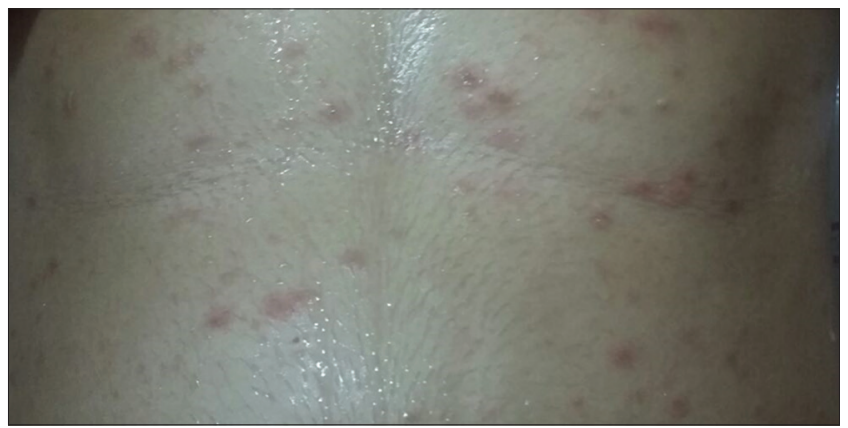

Fig. 1: Oval Slamon colored lesions in trunk 


\section{REFERENCES}

1. Stulberg DL, Wolfrey J. Pityriasis rosea. Am Fam Physician 2004;69(1):87-91.

2. González LM, Allen R, Janniger CK, Schwartz RA. Pityriasis rosea: An important papulosquamous disorder. Int J Dermatol 2005;44(9):757-64.

3. Chuh A, Lee A, Zawar V, Sciallis G, Kempf W. Pityriasis rosea - An update. Indian J Dermatol Venereol Leprol 2005;71(5):311-5.

4. Drago F, Broccolo F, Rebora A. Pityriasis rosea: An update with a critical appraisal of its possible herpesviral etiology. J Am Acad Dermatol 2009;61(2):303-18.
5. Gibson CS, Goldwater PN, MacLennan AH, Haan EA, Priest K, Dekker GA. South Australian cerebral palsy research group. Fetal exposure to herpesviruses may be associated with pregnancy-induced hypertensive disorders and preterm birth in a Caucasian population. BJOG 2008;115(4):492-500.

6. Drago F, Broccolo F, Zaccaria E, Malnati M, Cocuzza C, Lusso P, et al. Pregnancy outcome in patients with pityriasis rosea. J Am Acad Dermatol 2008;5 85 Suppl 1:S78-83.

7. Bianca S, Ingegnosi C, Ciancio B, Gullotta G, Randazzo L, Ettore G. Pityriasis rosea in pregnancy. Reprod Toxicol 2007;24(3-4):277-8. 